\title{
Model Persamaan Faktor Koreksi pada Proses Sedimentasi dalam Keadaan Free Settling
}

\author{
Roessiana D L; Setiyadi dan Sandy BH \\ Jurusan Teknik Kimia \\ Universitas Katolik Widya Mandala Surabaya \\ Email: setwmtk@gmail.com
}

\begin{abstract}
Abstrak
Sedimentasi adalah proses pengendapan padatan yang terkandung dalam cairan oleh gaya gravitasi. Pada umumnya proses sedimentasi dilakukan setelah proses koagulasi dan flokulasi, tujuannya adalah untuk memperbesar partikel padatan agar menjadi lebih berat dan dapat tenggelam dalam waktu lebih singkat. Ukuran dan bentuk partikel mempengaruhi rasio permukaan terhadap volume partikel sedangkan konsentrasi partikel mempengaruhi pemilihan tipe bak sedimentasi. Semua factor ini mempengaruhi kecepatan mengendap partikel pada sedimentasi, karena itu membutuhkan kecepatan turunnya partikel untuk mendesain bak sedimentasi yang efektif dan efisien.

Tujuan dari penelitian ini adalah untuk memperkirakan bentuk bentuk persamaan empiric yang merupakan faktor koreksi sebagai fungsi konsentrasi slurry mula-mula serta diameter partikel. Persamaan faktor koreksi dibuat berdasarkan data hasil perhitungan dari persamaan Stokes-Newton, Farag, Fergusson-Church serta persamaan Gibbs-Mathew-Link ternadap data percobaan. Percobaan yang dilakukan adalah mula-mula gaplek dihancurkan kemudian dicampur air lalu dimasukkan ke dalam tabung kaca setinggi $100 \mathrm{~cm}$. Tinggi lapisan padatan yang turun ke bawah dicatat tingginya tiap 3 menit, pencatatan dihentikan setelah beda tinggi lapisan padatan yang diukur tiap 3 menit sudah mulai menurun. Percobaan dilakukan dengan menvariasikan konsentrasi tepung tapioka dalam umpan dari 0,5\% sampai 5\%, serta diameter partikel antara 0,057 mm sampai 0,1245 mm.

Dari hasil penelitian dapat ditarik kesimpulan bahwa persamaan F yang paling cocok adalah bila dikalikan dengan Farag Law dengan persamaan $F=480.941 . X_{1}^{(0,0751)} \cdot X_{2}^{(1,7777)}$. Jadi persamaan kecepatan sedimentasi yang paling baik adalah :

$\mathrm{V}=\frac{g d_{p}^{2}\left(\rho_{s}-\rho_{f}\right) \varepsilon_{f}^{2}}{18 \mu_{f} b} . F$
\end{abstract}

Kata Kunci : Sedimentasi, kecepatan sedimentasi, faktor koreksi

\section{A. PENDAHULUAN}

Salah satu cara pemisahan antara padatan dengan cairan dari suatu slurry dapat dilakukan secara sedimentasi. Sedimentasi adalah suatu proses pengendapan padatan dalam cairan karena adanya gaya gravitasi. Ketika suatu partikel padatan berada pada jarak yang cukup jauh dari dinding atau partikel padatan lainnya kecepatan jatuhnya tidak dipengaruhi oleh gesekan dinding maupun dengan partikel lainnya, peristiwa ini disebut free settling. Ketika partikel padatan berada pada keadaan saling berdesakan maka partikel akan mengendap pada kecepatan rendah, peristiwa ini disebut hindered settling (Geankoplis, 2003). Akibat dari hal ini, pada proses sedimentasi kecepatan endapan yang turun ke bawah semakin lama semakin lambat, sehingga untuk memperoleh hasil sedimentasi sampai proses pengendapan berhenti memerlukan waktu yang cukup lama. Guna 
menghasilkan proses sedimentasi yang optimum perlu menentukan waktu pengendapan yang efektif. Proses sedimentasi banyak terjadi pada proses penjernihan air, pengolahan limbah, maupun erosi. Pada umumnya proses sedimentasi dilakukan setelah proses koagulasi dan flokulasi, tujuannya adalah untuk memperbesar partikel padatan sehingga menjadi lebih berat dan dapat tenggelam dalam waktu lebih singkat. Ukuran dan bentuk partikel akan mempengaruhi rasio permukaan terhadap volume partikel, sedangkan konsentrasi partikel mempengaruhi pemilihan tipe bak sedimentasi, serta temperatur mempengaruhi viskositas dan berat jenis cairan. Semua faktor ini mempengaruhi kecepatan pengendapan partikel pada bak sedimentasi. Karena itu membutuhkan kecepatan turunnya partikel guna mengetahui proses sedimentasi yang efektif dan efisien. Waktu pengendapan yang efektif dapat diasumsikan sebagai batas saat terjadi perubahan pengendapan dari free settling ke hindered settling, sehingga proses pengendapan yang efektif terjadi pada keadaan free settling. Cara menentukan kecepatan pengendapan dalam keadaan free settling, dapat dilakukan dengan persamaan Stokes-Newton, Farag, Ferguson-Church, maupun dengan persamaan GibbsMathew-Link. Namun semua persamaan tersebut akan menghasilkan ralat yang besar, sehingga memperlukan suatu metode guna memperoleh hasil perhitungan dengan ralat yang kecil (Setiyadi, 2013). Salah satu cara yang dapat dilakukan dengan menentukan faktor koreksi lalu dikalikan ke dalam setiap persamaan tersebut. Oleh karena itu penelitian ini bertujuan untuk membuat persamaan faktor koreksi agar dapat menghasilkan ralat yang kecil bila perhitungan menggunakan persamaan Stokes-Newton, Farag, Fergusson-Church, serta persamaan Gibbs-Mathew-Link.

\section{B. TINJAUAN PUSTAKA}

\section{Mekanisme Sedimentasi}

Tahapan sedimentasi dideskripsikan dengan observasi pada tes batch settling ketika partikelpartikel padatan mengendap dari suatu slurry dalam silinder kaca (Foust, 1980). Gambar 1.(a) menunjukkan slurry dalam silinder dengan konsentrasi padatan yang seragam. Seiring dengan berjalannya waktu, partikel-partikel padatan mulai mengendap dan laju mengendapnya partikel tersebut diasumsi sebagai terminal velocity. Pada Gambar 1.(b) terdapat beberapa zona konsentrasi. Daerah D didominasi endapan partikel-partikel padatan yang lebih berat dan lebih cepat mengendap. Pada zona $\mathrm{C}$ terdapat partikel dengan ukuran yang berbeda-beda dan konsentrasi yang tidak seragam. Daerah B adalah daerah dengan konsentrasi yang seragam dan hampir sama dengan keadaan mula-mula. Pada daerah B ini partikel-partikel turun dengan bebas hambatan dan terjadi proses free settling. Di atas daerah B adalah daerah A yang berupa liquid jernih. Jika sedimentasi 
dilanjutkan, tinggi dari tiap daerah bervariasi seperti pada Gambar 1.(c) dan Gambar 1.(d). Daerah A dan D semakin luas, sebanding dengan berkurangnya daerah B dan C. Pada akhirnya daerah B dan $\mathrm{C}$ akan hilang dan semua padatan terdapat pada daerah D sehingga hanya tersisa daerah A dan D. Keadaan seperti ini disebut dengan "Critical Settling Point" (Gambar 1.(e), yaitu keadaan dimana terbentuk bidang batas tunggal antara liquid jernih dan endapan.

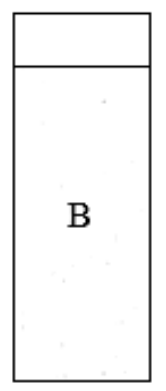

(a)

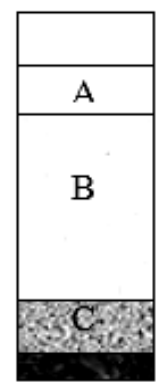

(b)

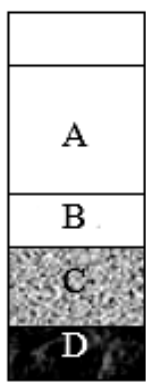

(c)

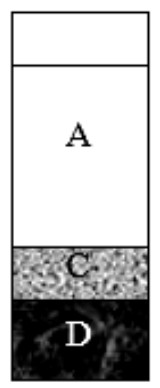

(d)

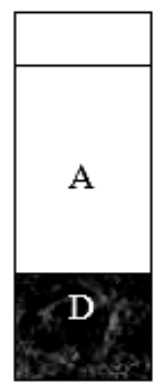

(e)

A. Clear Liquid; B. Uniform Concentration; C. Variable size and concuntration zone; D. Coarse Solid

Gambar 1. Tahapan Proses Pengendapan

\section{Kecepatan Sedimentasi}

Pada proses pengendapan dalam keadaan free settling, model persamaan yang dapat digunakan untuk menghitung kecepatan penurunan partikel pada proses sedimentasi adalah sebagai berikut:

\section{Stokes- Newton Law}

Jika sebuah partikel turun di dalam fluida karena gaya gravitasi, maka kecepatan pengendapan akan tercapai apabila jumlah dari gaya friksi (drag force) dan gaya apung (buoyancy) sebanding dengan gaya gravitasi benda (Sukardjo, 2004).

Persamaan kecepatan pengendapan adalah sebagai berikut :

$$
v_{s}=\frac{g D_{s}^{2}\left(\rho_{s}-\rho\right)}{18 \mu}
$$

Dimana vs adalah kecepatan pengendapan, g percepatan gravitasi, Ds diameter partikel, $\rho$ s densitas partikel, $\rho$ densitas cairan, dan $\mu$ viskositas cairan.

\section{Persamaan Farag}

Farag merumuskan suatu persamaan untuk kecepatan sedimentasi dengan variabel konsentrasi cairan. Persamaannya dapat dirumuskan (Farag, 1996): 


$$
v=\frac{g d_{p}^{2}\left(\rho_{s}-\rho_{f}\right) \varepsilon_{f}^{2}}{18 \mu_{f} b}
$$

\section{Persamaan Fergusson-Church}

Persamaan kecepatan pengendapan dapat dirumuskan (Ferguson, 2004)

$$
v_{s}=\frac{\rho_{s} g D^{2}}{18 \mu+\sqrt{0,3 \rho_{s} \rho g D^{3}}}
$$

Dimana vs adalah kecepatan pengendapan, g percepatan gravitasi, D diameter partikel, $\rho$ s densitas partikel, $\rho$ densitas air, dan $\mu$ viskositas air.

\section{Persamaan Gibbs-Mattew-Link}

Persamaan ini mengungkapkan hubungan antara ukuran partikel berbentuk bola dan kecepatan free settlingnya untuk berbagai temperatur, viskositas dan kepadatan bola. Untuk menghitung kecepatan pengendapan partkel berbentuk bola dari berbagai ukuran, dengan menggunakan pengolahan data yang diubah kedalam persamaan empiris memberikan hasil di bawah ini,

$$
v=\frac{-3 \eta+\sqrt{9 \eta^{2}+g r^{2} \rho_{f}\left(\rho_{s}-\rho_{f}\right)(0.015476+0.19841 r)}}{\rho_{f}(0.011607+0.14881 r)}
$$

Dimana $v$ kecepatan pengendapan, $\eta$ viskositas fluida, g percepatan gravitasi, $\rho f$ densitas fluida, $\rho$ densitas solid dan $\mathrm{r}$ jari-jari partikel.

\section{Persamaan Linierisasi Faktor Koreksi.}

Hubungan antara waktu pengendapan dan tinggi endapan akan membentuk grafik yang serupa pada semua proses sedimentasi, sehingga data-data pada proses sedimentasi dapat diubah ke dalam bentuk persamaan matematika yang serupa. Bila data dibuat kurva dan bisa dianggap menunjukkan bentuk garis lurus maka bentuk linier yang diperoleh dapat dengan mudah dibawa ke bentuk hubungan kurva dari peubah asalnya. Cara linierisasi hubungan kurva dari data ini banyak dipakai dalam menentukan bentuk persamaan empiric (Tyoso, 1991). Persamaan empirik yang dapat diselesaikan secara linierisasi diantaranya adalah : 


$$
\begin{aligned}
& F=a+b X \\
& F=a \cdot X^{b} \\
& F=a e^{b \cdot x} \\
& F=a \cdot b^{x} \\
& F=a+\frac{b}{X}
\end{aligned}
$$

\section{METODE PENELITIAN}

Cara percobaan yang dilakukan adalah mula-mula gaplek dihancurkan kemudian diayak hingga memperoleh ukuran butir-butir tepung sesuai variabel yang digunakan. Mencampur air, zat pewarna, dan serbuk gaplek dalam tangki, kemudian diaduk sampai homogen lalu dimasukkan ke dalam tabung kaca setinggi $100 \mathrm{~cm}$. Tinggi lapisan padatan yang turun ke bawah dicatat tingginya tiap 3 menit, pencatatan dihentikan setelah beda tinggi lapisan padatan tiap 3 menit sudah mulai menurun. Percobaan dilakukan dengan menvariasikan konsentrasi tepung tapioka dalam umpan yaitu 0,5\%, $1 \%, 2 \%, 3 \%, 4 \%$ dan $5 \%$ serta ukuran diameter partikel yang digunakan yaitu 80-100mesh, 100120mesh, 120-140mesh, 140-170mesh, dan 170-200 mesh.

\section{ANALISA}

Karena penelitian memvariasikan 2 variabel yaitu konsentrasi zat yang akan diendapkan dan diameter partikel maka persamaan (5) sampai (9) diubah menjadi sebagai berikut :

$$
\begin{aligned}
& F=a+b_{1} \cdot X_{1}+b_{2} \cdot X_{2} \\
& F=a \cdot X_{1}^{b 1}+\cdot X_{2}^{b 2} \\
& F=a \cdot e^{b 1 \cdot X 1} \cdot e^{b 2 \cdot X 2} \\
& F=a \cdot b_{1}^{X 1} \cdot b_{2}^{X 2} \\
& F=a+\frac{b_{1}}{X_{1}}+\frac{b_{2}}{X_{2}}
\end{aligned}
$$

Dimana $\mathrm{X}_{1}$ adalah konsentrasi gaplek dalam umpan dan $\mathrm{X}_{2}$ adalah diameter partikel.

Cara perhitungan parameter $a, b_{1}$, dan $b_{2}$ dilakukan dengan cara mula-mula menghitung kecepatan sedimentasi dengan memakai persamaan Stoke's-Newton pada persamaan (1) misal harga yang dihitung $=\mathrm{v} 1$. Menghitung kecepatan sedimentasi pada hasil percobaan dengan memakai persamaan 
$\mathrm{Vn}=(\mathrm{Zn}-\mathrm{Zn}-1) / 180$ Dimana $\mathrm{Z}$ adalah tinggi lapisan endapan serbuk gaplek pada percobaan serta $\mathrm{n}$ adalah nomor data percobaan. Perhitungan hanya digunakan harga $Z_{n}-Z_{n+1}$ masih dapat dianggap sama. Harga kecepatan sedimentasi dari data percobaan $v_{x}=\left(\sum V_{x}\right) / n$. Harga $F$ dihitung dengan $b$ cara $\mathrm{F}=\mathrm{v}_{\mathrm{x}} / \mathrm{v}_{1}$. Harga $\mathrm{F}$ ini kemudian dimasukkan ke persamaan (10) sampai (14) guna memperoleh harga $a, b_{1}$, dan $b_{2}$. dengan metode regresi linier ganda. Perhitungan ini diulang kembali namun menggunakan persamaan Farag, Fergusson-Church, serta persamaan Gibbs-Mathew-Link.

\section{E. HASIL PENELITIAN DAN PEMBAHASAN}

Percobaan ini dilakukan dengan variasi diameter partikel antara $0,057 \mathrm{~mm}$ sampai $0,1245 \mathrm{~mm}$ serta variasi konsentrasi dari $0.5 \%-5 \%$.

Dalam percobaan ini, persamaan yang digunakan adalah persamaan Stokes-Newton Law, Farag Law, Fergusson-Church, dan persamaan Gibb-Mattew-Link. Untuk menyesuaikan persamaanpersamaan ini data yang digunakan dalam percobaan hanya data pada saat free settling. Pada free settling, gesekan antar partikel tidak berpengaruh terhadap kecepatan sedimentasi, sehingga kecepatan sedimentasi memiliki mekanisme yang sama dengan gerak jatuh bebas. Persamaan StokesNewton Law, Fergusson-Church, dan persamaan Gibb-Mattew-Link menggunakan prinsip gerak jatuh bebas sebagai dasar teorinya. Dari hasil percobaan yang berupa perhitungan $a, b_{1}, b_{2}$ dan $R^{2}$ yang didapatkan hubungan antara diameter partikel serta konsentrasi mula-mula terhadap F. M Persamaan linier yang didapatkan dengan menggunakan sigmaplot disajikan pada tabel pada 1 sampai tabel 5 dengan hasil sebagai berikut.

Tabel 1. Bentuk Persamaan $F=a+b_{1} \cdot X_{1}+b_{2} \cdot X_{2}$

\begin{tabular}{|r|l|l|c|}
\hline No. & $\begin{array}{c}\text { Untuk Persamaan dari } \\
\text { Literature }\end{array}$ & \multicolumn{1}{|c|}{ Persamaan dari hasil Penelitian } & $\begin{array}{c}\text { Harga } \\
\mathbf{R}^{\mathbf{2}}\end{array}$ \\
\hline 1 & Stoke-Newton Law & $\mathrm{F}=0,1061+180,87 \mathrm{X}_{1}-0,0171 \mathrm{X}_{2}$ & 0,3022 \\
\hline 2 & Farag Law & $\mathrm{F}=-23,5039-803.067 \mathrm{X}_{1}-208,4206 \mathrm{X}_{2}$ & 0,8148 \\
\hline 3 & Fergusson-Church Law & $\mathrm{F}=0,0676+338,25 \mathrm{X}_{1}-0,0147 \mathrm{X}_{2}$ & 0,4251 \\
\hline 4 & Gib-Mattew-Link Law & $\mathrm{F}=-0,6256+53.540 \mathrm{X}_{1}-59,7150 \mathrm{X}_{2}$ & 0,4979 \\
\hline
\end{tabular}


Tabel 2. Bentuk Persamaan $F=a \cdot X_{1}{ }^{b 1} \cdot X_{2}{ }^{b 2}$

\begin{tabular}{|r|l|l|r|}
\hline No. & $\begin{array}{c}\text { Untuk Persamaan dari } \\
\text { Literature }\end{array}$ & \multicolumn{1}{|c|}{ Persamaan dari hasil Penelitian } & $\begin{array}{c}\text { Harga } \\
\mathbf{R}^{\mathbf{2}}\end{array}$ \\
\hline 1 & Stoke-Newton Law & $\mathrm{F}=1,0798 \times 10^{-4} \cdot \mathrm{X}_{1}^{(-0,3582) \cdot} \mathrm{X}_{2}^{(-0,1721)}$ & 0,0389 \\
\hline 2 & Farag Law & $\mathrm{F}=480.941 . \mathrm{X}_{1}^{(0,0751)} \cdot \mathrm{X}_{2}^{(1,7777)}$ & 0,9395 \\
\hline 3 & Fergusson-Church Law & $\mathrm{F}=0,0383 \cdot \mathrm{X}_{1}^{(0,1616)} \cdot \mathrm{X}_{2}^{(-0,4619)}$ & 0,5134 \\
\hline 4 & Gib-Mattew-Link Law & $\mathrm{F}=1.695 .011 \mathrm{X}_{1}^{(1,6413)} \cdot \mathrm{X}_{2}^{(-0,4619)}$ & 0,7336 \\
\hline
\end{tabular}

Tabel 3. Bentuk Persamaan $\mathrm{F}=\mathrm{ae}^{\mathrm{X} 1 . \mathrm{b} 1} \cdot \mathrm{ae} \mathrm{X}^{\mathrm{X} . \mathrm{b} 2}$

\begin{tabular}{|r|l|l|c|}
\hline No. & $\begin{array}{c}\text { Untuk Persamaan dari } \\
\text { Literature }\end{array}$ & \multicolumn{1}{|c|}{ Persamaan dari hasil Penelitian } & $\begin{array}{c}\text { Harga } \\
\mathbf{R}^{\mathbf{2}}\end{array}$ \\
\hline 1 & Stoke-Newton Law & $\mathrm{F}=0,1069 \cdot \mathrm{e}^{\mathrm{X} 1 \cdot(-2.771,8461)} \cdot 0,1069 \cdot \mathrm{e}^{\mathrm{X} 2 \cdot(-12,2302)}$ & 0,0568 \\
\hline 2 & Farag Law & $\mathrm{F}=23,4084 \cdot \mathrm{e}^{\mathrm{X} 1 \cdot(1.173,1193)} \cdot 3,4084 \cdot \mathrm{e}^{\mathrm{X} \cdot(82,3674)}$ & 0,7895 \\
\hline 3 & Fergusson-Church Law & $\mathrm{F}=0,0745 \cdot \mathrm{e}^{\mathrm{X} \cdot(2.703,1008)} \cdot 0,0745 \cdot \mathrm{e}^{\mathrm{X} \cdot(23,4476)}$ & 0,5256 \\
\hline 4 & Gib-Mattew-Link Law & $\mathrm{F}=0,7057 \cdot \mathrm{e}^{\mathrm{X} \cdot(19.568,5068)} \cdot 0,7057 \cdot \mathrm{e}^{\mathrm{X} 2 \cdot(-23,4476)}$ & 0,7641 \\
\hline
\end{tabular}

Tabel 4. Bentuk Persamaan $F=a \cdot b_{1}{ }^{\mathrm{X} 1} \cdot \mathrm{b}_{2}{ }^{\mathrm{X} 2}$

\begin{tabular}{|c|c|c|c|}
\hline No. & $\begin{array}{c}\text { Untuk Persamaan dari } \\
\text { Literature }\end{array}$ & Persamaan dari hasil Penelitian & $\begin{array}{c}\text { Harga } \\
\mathbf{R}^{2}\end{array}$ \\
\hline 1 & Stoke-Newton Law & $\mathrm{F}=0,1069 \cdot \mathrm{e}^{\mathrm{X} 1 \cdot(-2.771,8461)} \cdot 0,1069 \cdot \mathrm{e}^{\mathrm{X} 2 \cdot(-12,2302)}$ & 0,0568 \\
\hline 2 & Farag Law & $\mathrm{F}=23,4084 \cdot \mathrm{e}^{\mathrm{X} 1 \cdot(1.173,1193)} \cdot 3,4084 \cdot \mathrm{e}^{\mathrm{X} 2 \cdot(82,3674)}$ & 0,7895 \\
\hline 3 & Fergusson-Church Law & $\mathrm{F}=0,0745 \cdot \mathrm{e}^{\mathrm{X} 1 \cdot(2.703,1008)} \cdot 0,0745 \cdot \mathrm{e}^{\mathrm{X} 2 \cdot(23,4476)}$ & 0,5256 \\
\hline 4 & Gib-Mattew-Link Law & $\mathrm{F}=0,7057 \cdot \mathrm{e}^{\mathrm{X} 1 \cdot(19 \cdot 568,5068)} \cdot 0,7057 \cdot \mathrm{e}^{\mathrm{X} 2 \cdot(-23,4476)}$ & 0,7641 \\
\hline
\end{tabular}

Tabel 5. Bentuk Persamaan $\mathbf{F}=a+\frac{b_{1}}{X_{1}}+\frac{b_{2}}{X_{2}}$

\begin{tabular}{|r|l|l|c|}
\hline No. & $\begin{array}{c}\text { Untuk Persamaan dari } \\
\text { Literature }\end{array}$ & \multicolumn{1}{|c|}{ Persamaan dari hasil Penelitian } & $\begin{array}{c}\text { Harga } \\
\mathbf{R}^{\mathbf{2}}\end{array}$ \\
\hline 1 & Stoke-Newton Law & $\mathrm{F}={ }_{0,0556-\frac{4,5875 \times 10^{-7}}{X_{1}}+\frac{0,0004}{X_{2}}}$ & 0,2523 \\
\hline 2 & Farag Law & $\mathrm{F}=728,6254+\frac{0,0025}{X_{1}}-\frac{4,4284}{X_{2}}$ & 0,5823 \\
\hline 3 & Fergusson-Church Law & $\mathrm{F}=_{0,0577-\frac{1,9350 \times 10^{-6}}{X_{1}}+\frac{0,0004}{X_{2}}}$ & 0,4069 \\
\hline 4 & Gib-Mattew-Link Law & $\mathrm{F}=7,0942-\frac{0,0005}{X_{1}}+\frac{0,0192}{X_{2}}$ & 0,4490 \\
\hline
\end{tabular}


Dari hasil percobaan yang didapatkan bahwa semakin kecil ukuran partikel yang digunakan maka membutuhkan waktu sedimentasi semakin lama karena kecepatan beda yang jatuh bebas dipengaruhi oleh massa partikel. Semakin kecil konsentrasi maka kecepatan sedimentasi makin besar karena peluang tumbukan antar partikel maikin kecil.

Dari tabel 1 sampai tabel 5 di atas memberikan hasil bahwa dari semua metode persamaan yang ada, hasil pengolahan data menunjukkan bahwa persamaan Farag Law mempunyai harga $\mathrm{R}^{2}$ yang paling besar, berarti dari semua tabel persamaan $\mathrm{F}$ yang paling cocok bila digabungkan dengan persamaan faktor koreksi adalah persamaan Farag Law. Dari semua tabel tersebut harga $\mathrm{R}^{2}$ terbesar terjadi pada tabel 2. dengan bentuk persamaan $F=a \cdot X_{1} b_{1} \cdot X_{2} b_{2}$ dengan $R^{2}=0,9395$. Berarti persamaan kecepatan sedimentasi yang paling baik adalah :

$\mathrm{V}=\frac{g d_{p}{ }^{2}\left(\rho_{s}-\rho_{f}\right) \varepsilon_{f}{ }^{2}}{18 \mu_{f} b} \cdot F$ dengan $\mathrm{F}=480.941 . \mathrm{X}_{1}{ }^{(0,0751)} \cdot \mathrm{X}_{2}{ }^{(1,7777)}$

\section{KESIMPULAN}

Dari percobaan ini, dapat ditarik kesimpulan:

1. Untuk persamaan F yang paling cocok adalah metode Farag Law dengan persamaan

$$
\mathrm{F}=480.941 . \mathrm{X}_{1}^{(0,0751)} \cdot \mathrm{X}_{2}^{(1,7777)}
$$

2. Persamaan kecepatan sedimentasi yang paling baik adalah

$$
\mathrm{V}=\frac{g d_{p}^{2}\left(\rho_{s}-\rho_{f}\right) \varepsilon_{f}^{2}}{18 \mu_{f} b} . F
$$

\section{DAFTAR PUSTAKA}

Farag I., 1996, Fluid Flow, East Williston, New York

Fergusson R.I. and Church M., 2004, Journal of Sedimentary Research, p.p. 933-937.

Foust A.S., 1980, Principle of Unit Operation, 4 ed., John Wiley and Sons, New York

Geankoplis, C.J., 2003, Transport Processes and Separation Process Principles, 4 ed., Pearson Education Intrnationl, Boston

Gibbs, R.J., Matthews, M.D, and Link, DA., 1971, The Relationship between sphere size and settling velocity: Journal of Sedimentary Petrology, Volume. 41, No. 1, p.p. 7-18. 
Setiyadi, 2013, Prediksi Kecepatan Sedimentasi dalam Keadaan Free Settling, Seminar Nasional Teknik Kimia Subardjo Brotohardjono X, UPN Veteran, Surabaya.

Sukardjo, 2004, Kimia Fisika, cetakan ke 3, PT. Rineka Cipta, Jakarta.

Tyoso B.W., 1991, Bahan Penataran Pengolahan Data Secara non Statistik, PT. Pupuk Sri Wijaya, Palembang. 